\title{
Acute stress-induced antinociception is cGMP-dependent but heme oxygenase-independent
}

\author{
P.G. Carvalho-Costa ${ }^{1}$, L.G.S. Branco ${ }^{2}$ and C.R.A. Leite-Panissi ${ }^{1,2}$ \\ ${ }^{1}$ Programa de Graduação em Psicobiologia, Faculdade de Filosofia, Ciências e Letras de Ribeirão Preto, \\ Universidade de São Paulo, Ribeirão Preto, SP, Brasil \\ ${ }^{2}$ Departamento de Morfologia, Fisiologia e Patologia Básica, Faculdade de Odontologia de Ribeirão Preto, \\ Universidade de São Paulo, Ribeirão Preto, SP, Brasil
}

\begin{abstract}
Endogenous carbon monoxide (CO), which is produced by the enzyme heme oxygenase ( $\mathrm{HO}$ ), participates as a neuromodulator in physiological processes such as thermoregulation and nociception by stimulating the formation of $3^{\prime}, 5^{\prime}-$ cyclic guanosine monophosphate (cGMP). In particular, the acute physical restraint-induced fever of rats can be blocked by inhibiting the enzyme $\mathrm{HO}$. A previous study reported that the HO-CO-cGMP pathway plays a key phasic antinociceptive role in modulating noninflammatory acute pain. Thus, this study evaluated the involvement of the HO-CO-cGMP pathway in antinociception induced by acute stress in male Wistar rats (250-300 g; $n=8 /$ group) using the analgesia index (Al) in the tail flick test. The results showed that antinociception induced by acute stress was not dependent on the HO-CO-cGMP pathway, as neither treatment with the HO inhibitor ZnDBPG nor heme-lysinate altered the Al. However, antinociception was dependent on cGMP activity because pretreatment with the guanylate cyclase inhibitor $1 \mathrm{H}-[1,2,4]$ oxadiazolo [4,3-a] quinoxaline-1-one (ODQ) blocked the increase in the Al induced by acute stress.
\end{abstract}

Key words: Heme oxygenase; Carbon monoxide; cGMP; Lateral cerebral ventricle; Acute stress; Antinociception

\section{Introduction}

The exposure of animals to threatening situations of either an innate or learned nature results in species-specific defensive behaviors, autonomic alterations and pain inhibition. These reactions are crucial for the survival of the species (1). In this context, an important component of the response to emergency situations is the decreased capacity to perceive pain. Indeed, a number of studies have shown that the antinociceptive system can be activated by a variety of external or environmental noxious stimuli and plays an important role in control of defensive affective behaviors (2). In this context, fear induced by conditioned or unconditioned aversive stimuli is known to inhibit behavioral responses to pain (3). The onset of analgesia can be explained by multiple mechanisms that may be activated, depending on the nature of the noxious stimulation, its intensity, and its duration (4). In fact, it has been demonstrated that acute stress can trigger an increase in pain threshold and promote antinociception. In contrast, chronic stress may not interfere with nociception because an adaptation to stressful stimuli may take place or may even promote hypernociception (5).

Endogenously formed $\mathrm{CO}$ arises from heme degradation in a reaction catalyzed by the enzyme heme oxygenase (HO) and has been reported to participate as a neuromodulator in a number of physiological processes including thermoregulation and nociception through the formation of $3^{\prime}, 5^{\prime}$-cyclic guanosine monophosphate (cGMP) (6-8). According to this notion, Steiner et al. (8) demonstrated that the restraint-induced fever of rats may be prevented with an intracerebroventricular (icv) microinjection of zincdeuteroporphyrin-2,4-bis glycol (ZnDPBG), a nonselective inhibitor of $\mathrm{HO}$. It has also been reported that the $\mathrm{HO}-$ CO-cGMP pathway plays a key phasic antinociceptive role in modulating noninflammatory acute pain (6). However, the involvement of this pathway in the modulation of stress-induced antinociception has not been assessed. Thus, in the present study, we evaluated the involvement of

Correspondence: C.R.A. Leite-Panissi, Faculdade de Odontologia de Ribeirão Preto, USP, 14040-904 Ribeirão Preto, SP, Brasil. Fax: +55-16-3633-0999. E-mail: christie@forp.usp.br 
the HO-CO-cGMP pathway in antinociception induced by acute stress, using the analgesia index (Al) in the tail flick test in rats.

\section{Material and Methods}

\section{Experimental procedure}

Experiments were performed on male Wistar rats weighing 250-300 g obtained from the animal facility of the Universidade de São Paulo, Ribeirão Preto, SP, Brazil. The animals were housed in a room with controlled temperature $\left(24 \pm 1^{\circ} \mathrm{C}\right)$ and a 12-h light/dark cycle (lights on at 6:00 am), with food and water ad libitum. The Animal Use and Ethics Committee of the Universidade de São Paulo, Ribeirão Preto approved all experimental procedures (protocol no. 07.1.997.53.4).

For surgical procedures, rats were anesthetized with ketamine and xylazine (75 and $10 \mathrm{mg} / \mathrm{kg}$, respectively, administered intramuscularly). Animals designated for experiments involving icv injection were restrained in a stereotaxic frame, and a stainless steel guide cannula was introduced into the right lateral cerebral ventricle (coordinates: $1.0 \mathrm{~mm}$ posterior, $1.6 \mathrm{~mm}$ lateral to midline, and 3.2$3.7 \mathrm{~mm}$ ventral to the skull surface) (9). Displacement of the meniscus in a water manometer ensured correct positioning of the cannula in the lateral ventricle. The cannulas were attached to the bone with stainless steel screws and acrylic cement. A tight fitting stylet was kept inside the guide cannula to prevent occlusion. After surgery, rats were treated with Pentabiotic $(0.3 \mathrm{~mL} / \mathrm{kg}$ im; Fort Dodge, Brazil $0.3 \mathrm{~mL} / \mathrm{kg}$ ). The experiments were initiated 1 week after surgery.

The nonselective $\mathrm{HO}$ inhibitor zinc deuteroporphyrin 2,4-bis glycol (ZnDPBG, $50 \mathrm{nmol} / 4 \mu \mathrm{L}$ ) and hemin used in this study were obtained from Porphyrin Products (Logan, USA). ZnDPBG was dissolved in $50 \mathrm{mmol} / \mathrm{L} \mathrm{Na} \mathrm{CO}_{3}$ and stored in the dark. Hemin was used to prepare $150 \mathrm{nmol} /$ $4 \mu \mathrm{L}$ heme-lysinate, an HO-CO-cGMP pathway inducer, as previously described (8). Heme-free preparations were used as amino acid (L-lysine) vehicle control solutions. The vehicle of the heme-lysinate solution consisted of $14.2 \mu \mathrm{mol} / \mathrm{mL}$ L-lysine, $5 \%$ ethanol, $40 \%$ propylene glycol, and $55 \%$ sterile water. The soluble guanylyl cyclase (sGC) inhibitor $1 \mathrm{H}-[1,2,4]$ oxadiazolo [4,3-a] quinoxaline-1-one (ODQ, $1.3 \mathrm{nmol} / 4 \mu \mathrm{L}$ ) was purchased from Tocris Cookson (USA) and dissolved in a vehicle consisting of $1 \%$ dimethylsulfoxide (DMSO) in pyrogen-free sterile saline. The doses used were based on previous studies (6). For icv injections, a 10- $\mu \mathrm{L}$ Hamilton syringe connected to a dental injection needle by a PE-10 catheter was used. At the time of drug administration, the stylet was replaced with the injection needle and $4 \mu \mathrm{L}$ of the studied drug was infused over a period of $1 \mathrm{~min}(6)$. To prevent reflux, the needle was kept inside the guide cannula for $40 \mathrm{~s}$ after completing the infusion.

Nociception was assessed with a tail flick apparatus.
Rats were restrained manually and placed on the apparatus, which measured time in seconds (latency) that the animal took to respond, that is, remove the tail away from the noxious thermal stimulus. A cut-off time of $6 \mathrm{~s}$ was used to prevent tissue damage. Before treatment was initiated, the response latency in seconds for each animal was determined three consecutive times at random intervals of 1 to $3 \mathrm{~min}$. After measurement of basal latency, animals were divided into 8 experimental groups and were then subjected to the tail flick test after various experimental treatments at intervals of $15 \mathrm{~min}$ up to a maximum of $120 \mathrm{~min}$.

Rats in the different experimental groups were exposed to acute stress by physical restraint for 120 min beginning $30 \mathrm{~min}$ after the injection. Restraint was carried out by placing the animal in a plastic tube $(15 \mathrm{~cm}$ in length and $5 \mathrm{~cm}$ in diameter).

The experiments were initiated 7 days after surgery. The rats were evaluated in the tail flick test to determine the baseline, then were microinjected icv, and after that were divided into 8 experimental groups ( $n=8 /$ group). In group 1 , the rats received the $\mathrm{HO}$ inhibitor, ZnDPBG $(50 \mathrm{nmol} / 4 \mu \mathrm{L})$, and in group 2, the $\mathrm{Na}_{2} \mathrm{CO}_{3}$ vehicle $(50 \mathrm{mmol} / 4 \mu \mathrm{L})$. In groups 3 and 4 , the rats received heme-lysinate $(150 \mathrm{nmol} /$ $4 \mu \mathrm{L}$ ) or the L-lysine vehicle solution $(4 \mu \mathrm{L})$, respectively. In groups 5 and 6 , the rats were microinjected with ODQ $(1.3 \mathrm{nmol} / 4 \mu \mathrm{L})$ or with the $1 \%$ DMSO vehicle $(4 \mu \mathrm{L}) 30 \mathrm{~min}$ before icv administration of the L-lysine vehicle solution $(4 \mu \mathrm{L})$. Finally, in groups 7 and 8 the rats received an icv injection of ODQ $(1.3 \mathrm{nmol} / 4 \mu \mathrm{L})$ or $1 \%$ DMSO vehicle $(4 \mu \mathrm{L}) 30 \mathrm{~min}$ before icv administration of heme-lysinate (150 nmol/4 $\mu \mathrm{L}$ ).

At the end of the experiments, rats were anesthetized with chloral hydrate $(10 \%, 0.35 \mathrm{~mL} / 100 \mathrm{mg}$ body weight, ip) and transcardially perfused with saline $(0.9 \% \mathrm{NaCl})$ followed by $10 \%$ formalin. The brains were then removed and fixed in $10 \%$ formalin. The material was submitted to routine histological processing and sections were observed microscopically, according to the description in the Paxinos and Watson atlas (9).

In each group, tail flick latency was normalized using an antinociception index $(\mathrm{Al})$ derived from the tail flick test according to the following formula: tail flick test-tail flick control/cutoff time-tail flick control, where tail flick control was the average of 3 tail-flick baseline latencies. Al represents the antinociception index tail flick test; latency is the time that the animal takes to initiate a response after the experimental treatment; baseline is the latency period in the control; the noxious thermal stimulus was stopped after $6 \mathrm{~s}$.

Data are reported as mean $\mathrm{Al} \pm \mathrm{SE}$ and were analyzed by repeated measures multivariate analysis of variance (two-way ANOVA), with the variables being time (repeated factor) and treatment (independent factor), followed by one-way ANOVA and the Newman-Keuls test. Data were considered to be statistically significant when $\mathrm{P}<0.05$. 

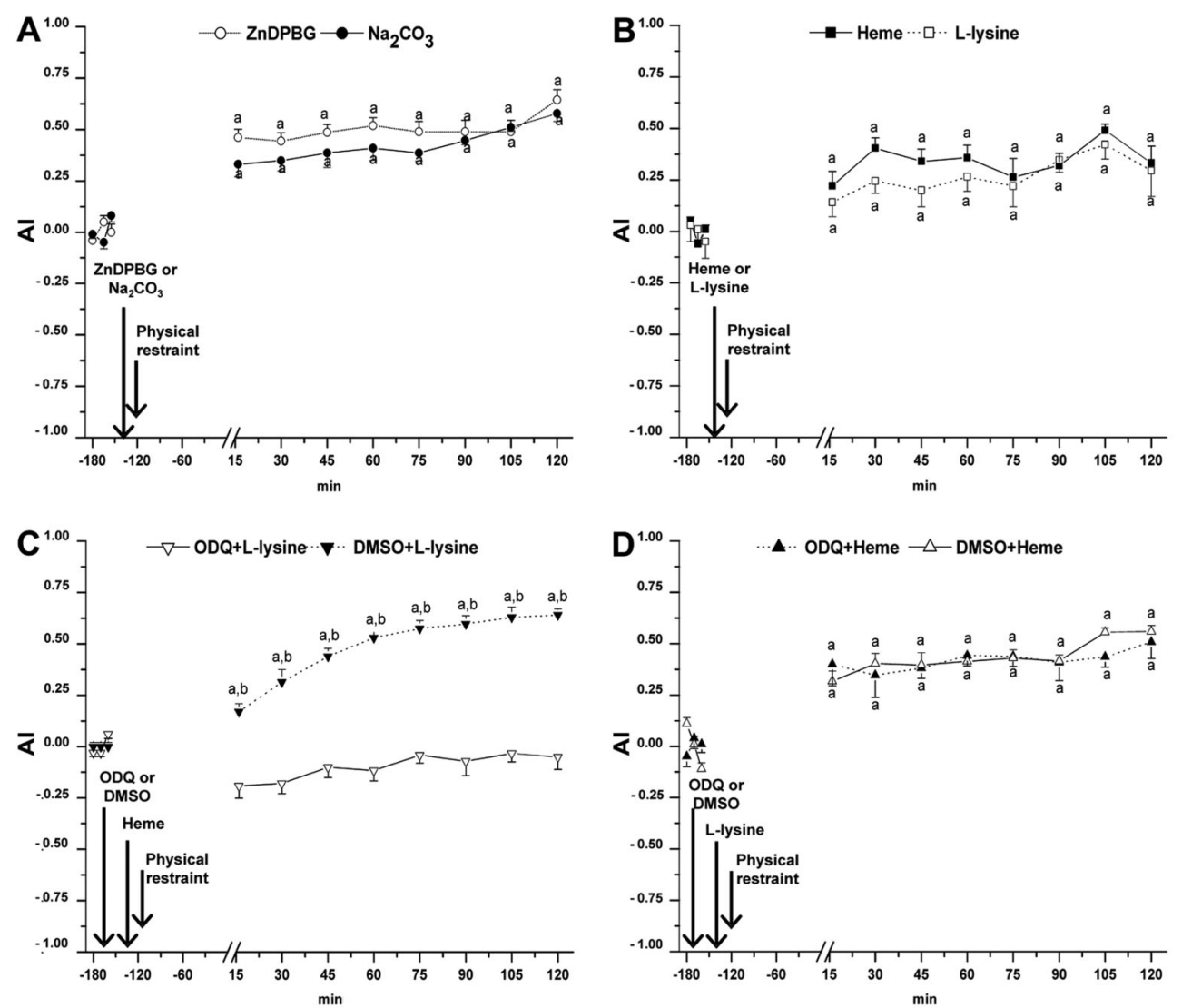

Figure 1. Antinociceptive index (Al) in the tail-flick test in rats. $A$, Administration (icv) of ZnDPBG (200 nmol/4 $\mu \mathrm{L}$, $\mathrm{HO}$ inhibitor) or vehicle $\left(\mathrm{Na}_{2} \mathrm{CO}_{3}\right)$. B, Administration (icv) of $\mathrm{HO}$ substrate heme-lysinate (Heme, $150 \mathrm{nmol} / 4 \mu \mathrm{L}$ ) or vehicle (L-lysine) on Al. C, Effect of icv injection of soluble guanylyl cyclase inhibitor (ODQ, $5.2 \mathrm{nmol} / 4 \mu \mathrm{L})$ or vehicle $(1 \% \mathrm{DMSO})$ followed 30 min later by L-lysine on $\mathrm{Al}$ in the tail flick test. $D$, Treatment (icv) of soluble guanylyl cyclase inhibitor (ODQ, $5.2 \mathrm{nmol} / 4 \mu \mathrm{L})$ or vehicle $(1 \%$ DMSO) followed $30 \mathrm{~min}$ later by heme-lysinate $(150 \mathrm{nmol} / 4 \mu \mathrm{L})$ on $\mathrm{Al}$ in the tail flick test. Data are reported as means $\mathrm{Al}( \pm \mathrm{SE}), \mathrm{n}=8$ in each group. a: $\mathrm{P}<0.05$, compared with respective control period; $b: \mathrm{P}<0.05$, ODQ + L-lysine group compared with DMSO + L-lysine group (Newman-Keuls test). The $\mathrm{Al}$ of the ODQ + L-lysine group did not differ over time when compared with the Al of the control period $(C)$.

\section{Results}

The results of the present study confirmed that acute stress induced antinociception (Figure 1), but neither heme-lysinate (an $\mathrm{HO}$ substrate, Figure 1B) nor ZnDPBG (an $\mathrm{HO}$ inhibitor, Figure $1 \mathrm{~A}$ ) altered the $\mathrm{Al}$ in rats that were evaluated using the tail flick test. However, the icv injection of the sGC inhibitor ODQ (Figure 1C) was able to block the increase in Al.

Statistical analysis (two-way ANOVA) showed that the Als of group 1, which received icv administration of ZnDPBG, and group 2, which received the vehicle $\left(\mathrm{Na}_{2} \mathrm{CO}_{3}\right)$, differed with time $\left[\mathrm{F}_{(8,143)}=26.76, \mathrm{P}<0.001\right]$ and treatment $\left[\mathrm{F}_{(1,143)}=\right.$ 12.97, $\mathrm{P}<0.001$ ], but that there was no interaction between time and treatment $\left[F_{(8,143)}=0.37, P=0.94\right]$. The post-hoc Newman-Keuls test showed that the Als in the ZnDPBG and $\mathrm{Na}_{2} \mathrm{CO}_{3}$ groups were different $(\mathrm{P}<0.05)$ at all experimental times when compared with the respective baseline values $(P<0.05$, Newman-Keuls test, Figure $1 \mathrm{~A})$.
Similarly, two-way ANOVA showed that the Als of group 3, treated with heme-lysinate (which induces the $\mathrm{HO}$ pathway), and group 4 , which received icv administration of the L-lysine vehicle solution, differed with time $\left[\mathrm{F}_{(8,143)}=\right.$ $5.83, P<0.001$ ], but there were no differences between the treatments $\left[F_{(1,143)}=3.62, P=0.06\right]$ or in the interaction between time and treatment $\left[F_{(8,143)}=0.015, P=0.94\right]$. The post-hoc Newman-Keuls test showed that the Als in the heme-lysinate and L-lysine groups were different $(P<0.05)$ throughout the experimental time when compared with the respective baseline $(P<0.05$, NewmanKeuls test, Figure 1B).

In groups 5 and 6 , which were treated with ODQ (a selective inhibitor of soluble guanylyl cyclase) or its vehicle (1\% DMSO) followed by L-lysine, two-way ANOVA revealed a difference with time $\left[\mathrm{F}_{(8,143)}=713.09, \mathrm{P}<0.001\right]$, and with treatment $\left[F_{(1,143)}=515.99, P<0.001\right]$ and the interaction of time and treatment $\left[\mathrm{F}_{(8,143)}=0.19, \mathrm{P}<0.001\right]$. The post hoc Newman-Keuls test showed that the Al of the ODQ+ 
L-lysine group was different from that of the DMSO+ L-lysine group $(\mathrm{P}<0.05)$ at each experimental time (Figure 1C). Additionally, the Al of the DMSO+L-lysine group was different $(P<0.05$, Newman-Keuls test) when compared with the respective baseline values. However, the $\mathrm{ODQ}+\mathrm{L}$-lysine group $\mathrm{Al}$ did not differ over time when compared with the baseline AI (Figure 1C).

Finally, two-way ANOVA applied to the Al of group 7, which received icv ODQ, or its DMSO vehicle (group 8), followed by heme-lysinate (which induces the HO pathway) showed differences with time $\left[\mathrm{F}_{(8,143)}=13.34, \mathrm{P}<0.001\right]$ but there was no difference with treatment $\left[F_{(1,143)}=0.21\right.$, $\mathrm{P}=0.64]$ nor was there an interaction of time and treatment $\left[F_{(8,143)}=0.42, P=0.91\right]$. The post-hoc Newman-Keuls test revealed that the Als of the heme-lysinate groups pretreated with ODQ or DMSO were different $(\mathrm{P}<0.05)$ over experimental time when compared with the respective baseline $(P<0.05$, Newman-Keuls test, Figure 1D).

\section{Discussion}

The present data showed that although cGMP is critical for the antinociceptive response induced by stress, stress analgesia is independent of the HO-CO-cGMP pathway. Additionally, our results confirmed previous studies $(4,5,10)$ reporting that acute stress produced by physical restraint was able to promote antinociception, as evidenced by the increase in the $\mathrm{Al}$, as evaluated using the tail flick test. In contrast, while the HO-CO-cGMP pathway is essential for restraint-induced fever, this system did not participate in restraint-induced analgesia.

Several previous studies have shown that different stress situations can promote antinociception in both opioid and nonopioid manners (3). Stress-induced analgesia is considered an adaptive response that occurs in both laboratory animals and humans. Thus, evidence shows that acute stress in rats (male and female) promotes increased latency of the tail flick test when compared with control animals that were not stressed, thereby demonstrating the antinociceptive effect of this manipulation (5).

Regarding the mechanisms involved in stress-induced analgesia, studies have reported both opioid-dependent and non-opioid mechanisms involving histaminergic, cholinergic, and serotonin neurotransmission, as well as the involvement of angiotensin and nitric oxide $(3,11)$. Correlating the angiotensin system, opioid and nociceptive modulation, a previous study (11) showed that administration of angiotensin II into the lateral ventricle of rats increased the latency of responses in the tail flick test. This increase was reversed by prior administration of naloxone, suggesting that the analgesia induced by angiotensin II was mediated by endogenous opioid mechanisms. However, analgesia produced by the activation of angiotensin receptors involved the activation of guanylyl cyclases because the administration of ODQ, a selective inhibitor of the GCs in the ventrolateral periaqueductal gray matter, was able to block angiotensin-induced antinociception in rats (12). Interestingly, evidence has consistently shown that angiotensin II is involved in the stress response (13). Additionally, the angiotensin $\mathrm{AT}_{1}$ receptor subtype has been found in the amygdala (14), which is a limbic structure known to be involved in the emotional response to stress (15). Moreover, some findings have demonstrated that restraint stress for 120 min enhanced antinociception, as assessed by the tail flick test in rats, and that this effect was blocked by treatment with an inhibitor of nitric oxide synthase (NOS), indicating that stress restraint-induced antinociception is dependent on the release of nitric oxide (10). The NO mechanism is similar to that of $\mathrm{CO}$, in that it involves an increase in the enzyme activity of GCs, thereby resulting in an increase in cGMP $(16,17)$. In fact, some evidence indicates that the antinociceptive effect of NO occurs through the activation of cGMP $(12,16,17)$. de Oliveira et al. (18) showed that restraint stress promotes increased expression of the neuronal enzyme NOS in the paraventricular nucleus of the hypothalamus, the medial nucleus of the amygdala and the dorsal periaqueductal gray matter. These brain areas have been closely related to nociceptive and antinociceptive modulation (19). The NO/cGMP system is involved in antinociception and in the effects produced by opioids (20) or the renin-angiotensin system (12). Taken together, these findings support the present data that the physical restraint stress promoted antinociception in the tail flick test, and this effect was blocked by pretreatment with ODQ, a GCs selective inhibitor. This evidence suggests that the antinociceptive effect was dependent on the activation of cGMP and was independent of the HO-CO-cGMP pathway, as neither a selective inhibitor of $\mathrm{HO}$ (ZnDPBG) nor an $\mathrm{HO}$ substrate (heme-lysinate) altered the increase in the Al induced by acute stress.

It is important to note that a previous report demonstrated that icv ZnDPBG administration did not affect the core body temperature of unrestrained rats but attenuated restraint-induced fever (8). In contrast, icv administration of heme-lysinate to unrestrained rats resulted in increased $\mathrm{Al}$, which was blocked by pretreatment with ZnDPBG or ODQ (6); however, icv treatment with either heme-lysinate or ZnDPBG did not alter the Al induced by acute stress in the present study. One plausible explanation is that the antinociception induced by restraint in the present study promoted the activation of CGMP, independent of the HOCO-cGMP pathway, and was blocked by pretreatment with ODQ (a selective inhibitor of soluble guanylyl cyclase).

\section{Acknowledgments}

The authors would like to thank Patricia Adriana Basile for her technical assistance. Research supported by CAPES/PROEX, FAPESP (\#07/08122-7). P.G. CarvalhoCosta has a PhD scholarship from CAPES. L.G.S. Branco and C.R.A. Leite-Panissi received research grants from CNPq (\#307383/2012-1 to C.R.A. Leite-Panissi). 


\section{References}

1. Fanselow MS. The midbrain periaqueductal gray as a coordinator of action in responsive to fear and anxiety. In: Depaulis A, Bandler R (Editors), The midbrain periaqueductal gray matter. New York: Plenum Press; 1991. p 151-173.

2. Fardin V, Oliveras JL, Besson JM. A reinvestigation of the analgesic effects induced by stimulation of the periaqueductal gray matter in the rat. I. The production of behavioral side effects together with analgesia. Brain Res 1984; 306: 105-123, doi: 10.1016/0006-8993(84)90360-3.

3. Rodgers RJ, Randall JI. Defensive analgesia in rats and mice. Psychol Rec 1987; 37: 335-347.

4. Curzon G, Hutson PH, Kennett GA, Marcou M. Characteristic of analgesia induced by brief or prolonged stress. Ann NY Acad Sci 1997; 93-101.

5. Gamaro GD, Xavier MH, Denardin JD, Pilger JA, Ely DR, Ferreira MB, et al. The effects of acute and repeated restraint stress on the nociceptive response in rats. Physiol Behav 1998; 63: 693-697, doi: 10.1016/S0031-9384(97)00520-9.

6. Carvalho PG, Branco LG, Panissi CR. Involvement of the heme oxygenase-carbon monoxide-cGMP pathway in the nociception induced by acute painful stimulus in rats. Brain Res 2011; 1385: 107-113, doi: 10.1016/j.brainres.2011.02.044.

7. Nascimento CG, Branco LG. Role of the peripheral heme oxygenase-carbon monoxide pathway on the nociceptive response of rats to the formalin test: evidence for a cGMP signaling pathway. Eur J Pharmacol 2007; 556: 55-61, doi: 10.1016/j.ejphar.2006.10.009.

8. Steiner AA, Reste G, Branco LG. Role of the brain heme oxygenase-carbon monoxide pathway in stress fever in rats. Neurosci Lett 2003; 341: 193-196, doi: 10.1016/S0304-3940 (03)00197-6.

9. Paxinos G, Watson C. The rat brain in stereotaxic coordinates. San Diego: Academic Press; 1998.

10. Echeverry MB, Guimaraes FS, Del Bel EA. Acute and delayed restraint stress-induced changes in nitric oxide producing neurons in limbic regions. Neuroscience 2004; 125: 981-993, doi: 10.1016/j.neuroscience.2003.12.046.

11. Raghavendra V, Chopra K, Kulkarni SK. Brain renin angiotensin system (RAS) in stress-induced analgesia and impaired retention. Peptides 1999; 20: 335-342, doi: 10.1016/ S0196-9781(99)00040-6.

12. Guethe LM, Pelegrini-da-Silva A, Borelli KG, Juliano MA, Pelosi GG, Pesquero JB, et al. Angiotensin (5-8) modulates nociception at the rat periaqueductal gray via the NO-sGC pathway and an endogenous opioid. Neuroscience 2013; 231: 315-327, doi: 10.1016/j.neuroscience.2012.11.048.

13. Walther T, Balschun D, Voigt JP, Fink H, Zuschratter W, Birchmeier C, et al. Sustained long term potentiation and anxiety in mice lacking the Mas protooncogene. J Biol Chem 1998; 273: 11867-11873, doi: 10.1074/jbc.273.19.11867.

14. Von Bohlen und Halbach O, Walther T, Bader M, Albrecht D. Interaction between Mas and the angiotensin AT1 receptor in the amygdala. J Neurophysiol 2000; 83: 20122021.

15. Ledoux J. The amygdala. Curr Biol 2007; 17: R868-R874, doi: 10.1016/j.cub.2007.08.005.

16. Almeida RT, Duarte ID. Nitric oxide/cGMP pathway mediates orofacial antinociception induced by electroacupuncture at the St36 acupoint. Brain Res 2008; 1188: 54-60, doi: 10.1016/j.brainres.2007.10.060.

17. Brito GA, Sachs D, Cunha FQ, Vale ML, Lotufo CM, Ferreira $\mathrm{SH}$, et al. Peripheral antinociceptive effect of pertussis toxin: activation of the arginine/NO/cGMP/PKG/ ATP-sensitive K channel pathway. Eur J Neurosci 2006; 24: 1175-1181, doi: 10.1111/j.1460-9568.2006.04991.x.

18. de Oliveira RM, Aparecida Del Bel E, Mamede-Rosa ML, Padovan CM, Deakin JF, Guimaraes FS. Expression of neuronal nitric oxide synthase mRNA in stress-related brain areas after restraint in rats. Neurosci Lett 2000; 289: 123126, doi: 10.1016/S0304-3940(00)01287-8.

19. Basbaum Al, Fields HL. Endogenous pain control systems: brainstem spinal pathways and endorphin circuitry. Annu Rev Neurosci 1984; 7: 309-338, doi: 10.1146/annurev.ne.07. 030184.001521.

20. Pol O. The involvement of the nitric oxide in the effects and expression of opioid receptors during peripheral inflammation. Curr Med Chem 2007; 14: 1945-1955, doi: 10.2174/ 092986707781368469 . 